RESEARCH ARTICLE

\title{
Economic Assessment of Direct Cost of Illness of Diabetes Mellitus at Dessie Referral Hospital, North East Ethiopia
}

\author{
Zinash Alemu ${ }^{1}$, Birhanu Demeke Workneh ${ }^{2 *}$, Solomon Ahmed Mohammed ${ }^{2}$ and Moges Workneh \\ Ayele $^{3}$ \\ ${ }^{1}$ Kazanchis Health Center, Addis Abeba, Ethiopia \\ ${ }^{2}$ Department of Pharmacy, College of Medicine and Health Science, Wollo University, Dessie, Ethiopia \\ ${ }^{3}$ Department of Pediatric Nursing, College of Medicine and Health Sciences, Wollo University, Dessie, Ethiopia
}

*Corresponding author: Birhanu Demeke Workneh, Department of Pharmacy, College of Medicine and Health Science, Wollo University, Dessie, Ethiopia

\begin{abstract}
Background: Diabetes Mellitus is a chronic disorder having major economic burden. Its progression and complication increase the medical cost.

Objective: To assess the direct cost of illness of diabetic mellitus treatment in Dessie Referral Hospital.

Method: Cross-sectional study was conducted on 217 participants from November 30, 2016 to December 31, 2017, and data were extracted from patients registries and analyzed using SPSS version 20. Linear regression was used to assess the statistically significant difference in the cost of treatment of diabetes. The study calculated direct medical and non- medical costs by multiplying the quantity of each service by their respective unit costs.
\end{abstract}

Results: The total direct medical and non-medical costs per year were 12721.5 USD where $86.5 \%$ was direct medical cost and $13.5 \%$ was direct non-medical cost. Total cost of oral anti-hyperglycemic agents was 1934.68 USD while the cost of illness of diabetic patients on insulin and syringes was 2962.6 USD and 751.16 USD respectively. Age, complication and comorbidity had a statistically significant $(p<0.05)$ effect on cost of illness.

Conclusion: Diabetes mellitus was an expensive illness and the direct medical costs constituted major segment in the treatment of illness, and treatment with insulin costs 1.5 times higher as compared with oral hypoglycemic agents. Diabetes mellitus cost burden has been accelerated due to its complications by 1.6. In view of the increasing global prevalence of diabetes, information from cost-of-illness studies should be used to increase awareness and for allocation of resources. Awareness of economic burden drives the urgent need for increased investments in the prevention and management of diabetes.

\section{Keywords}

Cost of illness, Comorbidity, Diabetic mellitus, Direct medical cost, Direct non-medical cost, Ethiopia

\section{Introduction}

Diabetes Mellitus is a group of metabolic disorder characterized by high blood glucose levels result from defect in insulin secretion or action, or both. Accordingly, there are two types and treatment varieties according to the cause [1]. Globally diabetes mellitus is an emerging common chronic illness with an estimated number of 220 million people in 2010.0f these approximately 12.1 million were living in Africa. In Sub Saharan Africa type 2 diabetes accounts for over $90 \%$ of diabetes [2]. In Ethiopia, the estimated prevalence of diabetes mellitus in adult population was 1.9\% [3] and the total diabetic cases were estimated to be 2.6 million by the year 2025 [4].

Diabetes imposes a large economic burden on the health care system and health spending on diabetes accounted $11.6 \%$ of total health expenditure worldwide in 2015 [5,6]. In Latin America and the Caribbean countries the annual estimated number of deaths was 339,035 accounted a loss of 757,096 and United Sta-

Citation: Alemu Z, Workneh BD, Mohammed SA, Ayele MW (2020) Economic Assessment of Direct Cost of Illness of Diabetes Mellitus at Dessie Referral Hospital, North East Ethiopia. Int J Diabetes Clin Res 7:122. doi.org/10.23937/2377-3634/1410122

Accepted: May 04, 2020: Published: May 06, 2020

Copyright: (C) 2020 Alemu Z, et al. This is an open-access article distributed under the terms of the Creative Commons Attribution License, which permits unrestricted use, distribution, and reproduction in any medium, provided the original author and source are credited. 
tes Dollar (USD) 3 billion discounted years of productive life and cost among persons younger than 65 years respectively in 2000 [7].

The medical cost of diabetes depends on its prevalence, types of drug used, and presence of co-morbidity, compliance of patient and development as well as progression of complication [8]. Diabetes costs approximately USD 10.43 billion direct costs and USD 14.79 billion indirect costs in United Kingdom in 2010/2011 and cost is estimated to be USD 17.98 billion direct USD 24.36 billion in indirect costs in 2035/2036 [9]. Type 2 diabetes mellitus in Iran also costs USD 2.0460.28 billion direct and USD 1.73 million indirect costs with USD 842.66102 and USD 864.8 average cost per capita respectively in 2009 [10].

Unhealthy diet and insufficient physical activity due to non-adherence, poor attitude and poor management by the health care professionals and patients were common cause of diabetic complication [11]. Permanent disability caused a loss of $12,699,087$ years and over $\$ 50$ billion, and temporary disability caused a loss of 136,701 years in the working population and over $\$ 763$ million in Latin America and the Caribbean countries [7]. In Iran, complications also accounted $48.9 \%$ of direct cost [10].

In most African countries, diabetic patients' lives with many complications incurring higher average monthly out of pocket expenses due to long term treatment duration [12], as complications require more laboratory investigations, hospitalization and multiple therapies [13]. In Ethiopia this problems are increasing for the last two to three decades and becoming a major economic factor as this made diabetes patients to be dropped out of treatment [3]. Access to care may also contribute for poor prognosis for people with diabetes [14].

Diabetes is a chronic disease requiring lifelong treatment and now a day's people in the world become cost oriented in medical care. In addition to high cost of medication, overall medical cost remains a very serious problem as progression and complication of disease increases. Therefore, estimation of cost of treatment has become more significant. Thus cost of illness studies identifies the cost related to disease by estimating and identifying the burden of disease, and possible priority setting areas for appropriate health programs implementation [15].

In Ethiopia, patient health seeking behavior is rising with an increasing health care resources allocation for new and more costly treatment modalities and these necessities clinicians' and decision makers to investigate the economic burden of diabetes mellitus. Therefore, this study aimed to assess the direct cost illness of diabetes in Dessie Referral Hospital from patient perspective. During the time of the study, the hospital didn't exercise health insurance and patients utilized service through out of pocket expenses.

\section{Methods and Materials}

\section{Study area and period}

The study was conducted in Dessie Referral Hospital from November 2016 to December 2017 located $401 \mathrm{~km}$ away from North-east of Addis Ababa, Ethiopia, Amhara region, South Wollo zone. Dessie Referral Hospital is large institution serving more than 7 million populations.

\section{Study design}

A cross sectional study design on prospective basis for one-year data was employed to collect data from patient medical charts or registries. The perspective for this study was patients of diabetic mellitus in Dessie Referral Hospital. The study also included direct costs.

\section{Source and study of population}

All patients who had followed-up to diabetes mellitus clinic of Dessie Referral Hospital were source of population and those patients who were availed during the data collection period were study population.

\section{Inclusion and exclusion criteria}

Among patients who came to diabetes mellitus clinic of Dessie Referral Hospital for follow up, those patients who had less than one-year follow, incomplete information on patient card, unable to listen and speak and who were not willing were excluded.

\section{Sample size and sampling technique}

The sample size was estimated by using single population proportion formula. To had a maximum sample size (384), 50\% prevalence, $95 \%$ confidence level and 5\% tolerable sampling error was used. Since the source population is less than 10,000 (500 new and chronic cases) and the sample was calculated using the adjustment formula and a total of 217 diabetes patients were included.

\section{Variables}

\section{Dependent variables}

The dependent variable of the study was direct cost of illness.

\section{Independent variables}

The independent variables were socio-demographic characteristics, types of diabetes, diabetic complications, duration of the diseases, presence of comorbid illness, fasting blood sugar level, number of visiting to diabetic per year and number of hospitalization and treatments including syringe.

\section{Data collection instrument}

A compressive checklist was used for data collection and validity of the study was ensured by pretest.

\section{Data analysis and presentation}

The present study only assessed the direct cost such 
as cost of drugs, transportation, laboratory test, personnel cost and cost of glucose meter. Costs were obtained from the pharmacy department of the hospital and the cost per defined daily dose were calculated taking duration of therapy into consideration to obtain total cost of drugs and the laboratory test costs also obtained from the laboratory of hospital. Service fee for transportation was obtained from South Wollo zone transport authority and transportation cost was determined by multiplying the number of trip by the respective cost. Personal and accommodation costs were based on patient report. The total medical cost includes direct cost incurred for hospitalization, outpatient visit and out of pocket expenditures.

The data were entered and analyzed using statistical package for social science (SPSS) version 20 and Microsoft Excel 2007 and the results were presented in the form of tables and graphs. Linear regression was used to assess the statistically significant difference in the cost of treatment of diabetes and variable with $p$-value $<0.05$ were taken as statistically significant. The study calculated direct medical costs and non-medical by multiplying the quantity of each service by their respective unit costs.

\section{Results}

\section{Socio-demographic characteristics}

From the total participant $56.2 \%$ were males. Among the total respondents $51.6 \%$ have health insurance scheme and $67.3 \%$ were reside from Dessie town (Table 1). Binary logistic regression results revealed that socio demographic characteristics of respondents does not have a statistically significant $(p>0.05)$ effect on complication of diabetes mellitus.

Table 1: Demographic characteristics of respondents $(n=217)$ in Dessie Referral Hospital, 2017.

\begin{tabular}{|c|c|c|c|}
\hline Categories & Number & Percent & P-value \\
\hline \multicolumn{3}{|l|}{ Age (Years) } & 0.259 \\
\hline$<35$ & 59 & 27.2 & \\
\hline $36-44$ & 43 & 19.8 & \\
\hline $45-54$ & 42 & 19.4 & \\
\hline $55-64$ & 48 & 22.1 & \\
\hline $65-74$ & 20 & 9.2 & \\
\hline$>74$ & 5 & 2.3 & \\
\hline \multicolumn{3}{|l|}{ Gender } & 0.133 \\
\hline Male & 122 & 56.2 & \\
\hline Female & 95 & 43.8 & \\
\hline Family history & & & 0.567 \\
\hline Absent & 157 & 72.9 & \\
\hline Present & 60 & 27.2 & \\
\hline \multicolumn{3}{|l|}{ Residence area } & 0.416 \\
\hline Dessie & 147 & 67.7 & \\
\hline Out of Dessie & 70 & 32.3 & \\
\hline \multicolumn{3}{|c|}{ Registered in health insurance scheme } & 0.457 \\
\hline Yes & 112 & 51.6 & \\
\hline No & 105 & 48.4 & \\
\hline
\end{tabular}

Table 2: Clinical characteristics of respondents $(n=217)$ in Dessie Referral Hospital, 2017.

\begin{tabular}{|l|l|l|l|}
\hline Categories & \multicolumn{2}{l|}{ Number } & \multicolumn{2}{l|}{ Percent } & P-value \\
\hline Duration of the disease (years) & \multicolumn{2}{l|}{} & 0.389 \\
\hline $3 / 12-1$ & 93 & 42.9 & \\
\hline $2-5$ & 99 & 45.6 & \\
\hline $6-10$ & 20 & 9.2 & \\
\hline $11-15$ & 3 & 1.4 & \\
\hline$\geq 15$ & 2 & 1 & 0.753 \\
\hline Fasting blood sugar level (mg/dl) & & & \\
\hline$<70$ & 7 & 3 & \\
\hline $70-139$ & 56 & 26 & \\
\hline $140-199$ & 68 & 31.3 & \\
\hline
\end{tabular}




\begin{tabular}{|l|l|l|l|}
\hline $200-299$ & 57 & 26.2 & \\
\hline$\geq 300$ & 29 & 13.3 & 0.944 \\
\hline Co-morbidity & \multicolumn{3}{|l|}{} \\
\hline With co morbid & 102 & 47 & \\
\hline Without co morbid & 115 & 53 & 0.089 \\
\hline Annual number of visit to diabetes clinic & & & \\
\hline $1-3$ visits & 4 & 1.9 & \\
\hline $4-7$ visits & 34 & 15.2 & \\
\hline $8-11$ visits & 62 & 28.5 & \\
\hline 12 or more visits & 117 & 54.4 & \\
\hline Total & 217 & 100.00 \\
\hline
\end{tabular}

Table 3: Total cost of individual drugs in Dessie Referral Hospital, 2017.

\begin{tabular}{|l|l|l|l|l|}
\hline Drug & Total cost (USD) & \% total drug cost & $\begin{array}{l}\text { Number of patients } \\
\text { involved }\end{array}$ & $\begin{array}{l}\text { \% of patients } \\
\text { involved }\end{array}$ \\
\hline Metformin & 1646 & 32.76 & 106 & 48.8 \\
\hline Glibenclamide & 288.68 & 5.7 & 84 & 38.7 \\
\hline Enalapril & 902.57 & 17.96 & 74 & 34.1 \\
\hline Nifedipine & 188.18 & 3.74 & 29 & 13.4 \\
\hline Hydro-chlorothiazide & 55.71 & 1.1 & 15 & 6.9 \\
\hline Simvastatin & 736.20 & 14.65 & 43 & 19.8 \\
\hline Furosemide & 39.89 & 0.79 & 8 & 3.7 \\
\hline Aspirin & 58.87 & 1.17 & 20 & 9.2 \\
\hline Atorvastatin & 310.66 & 6.18 & 10 & 3.2 \\
\hline Others & 798.00 & 15.95 & 25 & 11.5 \\
\hline Total & 5024.95 & 100 & & \\
\hline
\end{tabular}

Others includes; Spirolactone, Atenolol, GI drugs, Antibiotics, Metoprolol, Clopidogrel.

Table 4: Cost of illness of Diabetes Mellitus patients on insulin in Dessie Referral Hospital, 2017.

\begin{tabular}{|l|l|l|l|}
\hline Cost component & Total cost (USD) & \% total cost & \% cost of illness \\
\hline Insulin & 2962.60 & 37 & 79.78 \\
\hline Syringes & 751.16 & 8.59 & 20.22 \\
\hline Total & 3713.76 & 45.59 & 100 \\
\hline
\end{tabular}

Annual visit of patients depend on their resident and of them $54.4 \%$ visited 12 and more than 12 . The mean duration of treatment was 1.75 years. Majority of them had checkup monthly. The fasting blood sugars levels of 26\% were 70-139 and from the total subjects, 102 $(47 \%)$ were with co-morbid. With regard to complications, $47(21.7 \%)$ were with acute complications (Table 2). Binary logistic regression result showed that clinical characteristics of respondents doesn't have a statistically significant $(p<0.05)$ effect on complication of diabetes mellitus.

\section{Direct cost of illness of diabetes}

The total cost of individual drugs for 109 diabetic patients on oral hypoglycemic agents was 5024.95 USD (Table 3) and of this oral hypoglycemic agent accounted USD 1934.68. The peak percentages of cost of illness on oral hypoglycemic agent patients were $48.8 \%, 38.7 \%$, and $34.1 \%$ for Metformin, Glibenclamide, and Enalapril respectively.

One-year cost of illness of diabetic patients on insulin was USD 2962.6 (Table 4). Treatment with insulin costs 1.5 times higher as compared with oral hypoglycemic agents. Diabetes mellitus complication also costs 1.6 times higher than patients without complication.

The total direct medical and non-medical cost per year was USD 12721.5 where $86.5 \%$ was direct medical cost and $13.5 \%$ was direct non-medical cost. From the total direct cost diabetes mellitus drugs accounted 68.69\% (Table 5).

The mean cost of illness varies across age groups and the highest was observed in 65-74 age (USD 83.55) while the smallest were less than 35 years of age (USD 38.72) (Table 6). Comparable mean cost of illness was found in male (USD 57.60) and female (USD 57.78). Only 
Table 5: Total cost of illness of diabetes mellitus in Dessie Referral Hospital, 2017.

\begin{tabular}{|l|l|l|}
\hline Cost component & Total cost (USD) & \% of cost of illness \\
\hline Drugs & 8738.31 & 68.69 \\
\hline FBS/RBS & 1632.50 & 12.83 \\
\hline Urine analysis & 575.00 & 4.52 \\
\hline Transport & 301.31 & 2.37 \\
\hline Glucose meter & 62.33 & 0.49 \\
\hline Personnel & 980.48 & 7.71 \\
\hline Accommodation cost & 431.14 & 3.39 \\
\hline Total & 9007.70 & 100 \\
\hline
\end{tabular}

Table 6: Mean cost of illness by demographic characteristics in Dessie Referral Hospital, 2017.

\begin{tabular}{|c|c|c|c|c|}
\hline Categories & Number & Percent & Mean cost of illness (USD) \pm SD & P-value \\
\hline \multicolumn{4}{|l|}{ Age (Years) } & 0.035 \\
\hline$<35$ & 59 & 27.2 & $38.72 \pm 14.63$ & \\
\hline $36-44$ & 43 & 19.8 & $48.58 \pm 19.63$ & \\
\hline $45-54$ & 42 & 19.4 & $63.99 \pm 56.94$ & \\
\hline $55-64$ & 48 & 22.1 & $73.38 \pm 51.02$ & \\
\hline $65-74$ & 20 & 9.2 & $83.55 \pm 62.68$ & \\
\hline$>74$ & 5 & 2.3 & $52.46 \pm 20.82$ & \\
\hline \multicolumn{4}{|l|}{ Gender } & 0.768 \\
\hline Male & 122 & 56.2 & $57.60 \pm 44.02$ & \\
\hline Female & 95 & 43.8 & $57.78 \pm 43.45$ & \\
\hline \multicolumn{4}{|l|}{ Family history } & 0.662 \\
\hline Absent & 157 & 72.9 & $54.64 \pm 34.43$ & \\
\hline Present & 60 & 27.2 & $58.93 \pm 46.83$ & \\
\hline \multicolumn{4}{|l|}{ Residence area } & 0.823 \\
\hline Dessie town & 147 & 67.7 & $57.87 \pm 46.78$ & \\
\hline Out of Dessie town & 70 & 32.3 & $57.28 \pm 36.61$ & \\
\hline \multicolumn{4}{|c|}{ Registered in health insurance scheme } & 0.645 \\
\hline Yes & 11 & 51.6 & $56.05 \pm 47.80$ & \\
\hline No & 105 & 48.4 & $59.25 \pm 39.58$ & \\
\hline
\end{tabular}

age from demographic characteristics had a statistically significant $(p<0.05)$ association on cost of illness by linear regression.

The highest mean cost of illness observed on11-15 years of duration of the disease (USD 130.19), 140-199 fasting blood sugar in mg/dl (USD 65.98), and the number of visit greater than 12 (USD 62.83) (Table 7). The mean cost of illness for complication (USD 75.28) and comorbidity (USD 77.44) diabetes mellitus was higher than those patients without complications and comorbidity respectively. From the clinical characteristics of diabetes patients' complication and comorbidity had a statistically significant effect on cost of illness ( $p<0.05)$.

\section{Discussion}

Diabetes is a chronic life style disease having numerous systemic and ocular manifestations. The age of onset of diabetes was decreasing, with peak occurrence ages of less than 35. This result was similar with Assefa, et al. [16] study for both diabetes types and Mutowo, et al. [17] study for type 2 diabetes. Similarly, diabetes mellitus had been present 15-19 years in 68 patients, 20-24 years in 29, 25-29 years in seven and 30 years in one [18]. Among diabetes patients, majority were males, having a family history of diabetes, and with registered health insurance scheme. We studied the association between complication and socio demographic characteristics of patients and there was no statistically significant association ( $p>0.05$ ) between them.

In the present study, majority of diabetic patients were from Dessie town. This showed further raise in the prevalence of diabetes in urban areas [19]. Even though people in the rural are more vulnerable for complications due to delay in diagnosis and incomplete follow-up and treatment, it does not have statistically significant ( $p>0.05$ ) effect for complication. Potential associations between diabetes and communicable diseases further complicate the pattern of increasing diabetes prevalen- 
Table 7: Mean cost of illness by patient clinical characteristics in Dessie Referral hospital, 2012.

\begin{tabular}{|c|c|c|c|c|}
\hline Categories & Number & Percent & Mean cost of illness (USD) \pm SD & P-value \\
\hline \multicolumn{4}{|c|}{ Duration of the disease (years) } & 0.667 \\
\hline $3 / 12-1$ & 93 & 42.9 & $53.34 \pm 49.94$ & \\
\hline $2-5$ & 99 & 45.6 & $56.98 \pm 36.26$ & \\
\hline $6-10$ & 20 & 9.2 & $69.98 \pm 26.23$ & \\
\hline $11-15$ & 3 & 1.4 & $130.19 \pm 94.70$ & \\
\hline$\geq 15$ & 2 & 1 & 94.62 & \\
\hline \multicolumn{4}{|c|}{ Fasting blood sugar level (mg/dl) } & 0.645 \\
\hline$<70$ & 7 & 3 & $48.73 \pm 17.15$ & \\
\hline $70-139$ & 56 & 26 & $54.61 \pm 26.83$ & \\
\hline $140-199$ & 68 & 31.3 & $65.98 \pm 52.66$ & \\
\hline $200-299$ & 57 & 26.2 & $51.92 \pm 35.53$ & \\
\hline$\geq 300$ & 29 & 13.3 & 53.76 & \\
\hline \multicolumn{4}{|l|}{ Complication } & 0.003 \\
\hline Yes & 58 & 26.7 & $75.28 \pm 54.85$ & \\
\hline No & 159 & 73.3 & $51.26 \pm 36.97$ & \\
\hline \multicolumn{4}{|l|}{ Types of DM } & 0.285 \\
\hline Type 1 & 75 & 34.3 & $48.99 \pm 30.89$ & \\
\hline Type 2 & 142 & 65.7 & $62.04 \pm 48.64$ & \\
\hline \multicolumn{4}{|l|}{ Co-morbidity } & $<0.0001$ \\
\hline With co morbid & 102 & 47 & $77.44 \pm 54.19$ & \\
\hline Without co morbid & 115 & 53 & $40.23 \pm 19.59$ & \\
\hline \multicolumn{4}{|c|}{ Annual numbers of visit to diabetes clinic } & 0.650 \\
\hline $1-3$ visits & 4 & 1.9 & & \\
\hline 4-7 visits & 34 & 15.2 & $38.05 \pm 22.86$ & \\
\hline $8-11$ visits & 62 & 28.5 & $56.48 \pm 35.90$ & \\
\hline 12 or more visits & 117 & 54.4 & $62.83 \pm 49.21$ & \\
\hline Total & 217 & 100.00 & & \\
\hline
\end{tabular}

ce in Sub-Saharan [2].

Regarding fasting blood glucose concentration, the highest (31.3\%) was observed for $140-199 \mathrm{mg} / \mathrm{dl}$, with no significant associations for complication. A meta-analysis of 102 prospective studies showed that fasting blood glucose concentration was non-linearly related to vascular risk, with no significant associations between $3.90 \mathrm{mmol} / \mathrm{L}$ and $5.59 \mathrm{mmol} / \mathrm{L}$ [20].

In the present study, $42.9 \%$ and $45.6 \%$ of diabetes in the study population occurred within the duration of less than 1 year and 1-5 years respectively. The result was similar with South Indian tertiary care hospital study where $60.8 \%$ of diabetic patients without complication had $<5$ years of history of diabetes [19]. Diabetes patients with comorbidity constituted $47 \%$ and $54.4 \%$ of them had more than 12 visits annually but it does not have statistically significant $(p>0.05)$ association for complication.

There is trend in the shift of age of onset of diabetes to a younger age in the recent years [21]. In sub-Saharan Africa diabetic population is in the economically productive age group of 30 to 45 years. The late dia- gnosis coupled with inequalities in accessing care leads to diabetic complications and it could have long lasting adverse effects on nation's health and economy [22]. So early screening of at risk individuals and appropriate intervention like weight reduction, diabetic compatible life style, improved compliance to medication and increased physical activity can greatly help to prevent, or at least delay, the onset of diabetes and its complication [21]. But the health sector alone cannot accomplish population wide changes to healthy lifestyles. Anthropological perspectives are needed to elucidate the causes, prevention, and control of diabetes [23].

The peak percentages of cost of illness on oral hypoglycemic agent patients were $48.8 \%, 38.7 \%, 34.1 \%$ and $14.6 \%$ for Metformin, Glibenclamide, Enalapril and Simvastatin respectively. This reveled that type2 diabetes is becoming more prevalent due to rising rates of obesity, physical inactivity, and urbanization [22]. In Nigeria, about $77 \%$ of the patient had hypertension as concurrent illness and were placed on antihypertensive drugs [24]. Cardio protective and obesity reduction effect of Enalapril and Simvastatin respectively might be responsible for their high degree of usage and the cost of indi- 
Table 8: Compression of cost of illness by various authors.

\begin{tabular}{|l|l|l|l|l|}
\hline & Present study & Abdulganiyu, et al. [24] & Suleiman, et al. [8] & Assefa, et al. [16] \\
\hline Cost component & & Cost USD (percentage) & & \\
\hline Drug & $8,738.31(68.69)$ & $11,597.59(84)$ & $5,517.45(86.2)$ & $8426.29(73.10)$ \\
\hline Diagnostic/Monitoring Tests & $2,269.83(17.84)$ & $250(1.8)$ & $358.57(5.6)$ & $1190.81(10.33)$ \\
\hline Transport & $301.31(2.37)$ & $1,553.33(11.2)$ & $182.69(2.9)$ & $866.94(7.52)$ \\
\hline Personnel & $1,411.62(11.1)$ & $416.67(3)$ & $343.14(5.4)$ & $1,046.64(9.07)$ \\
\hline Total & $12,721.5$ & $13,817.59$ & $6,401.85$ & $11,530.68$ \\
\hline
\end{tabular}

vidual drugs can be a major burden as the diseases does not have cure.

In the present study, total direct medical and non-medical cost per year was USD 12721.5 where $86.5 \%$ was direct medical cost and $13.5 \%$ was direct non-medical cost. The total annual cost associated with diabetes in Latin America and the Caribbean was estimated USD 65,216 million (direct 10,721; indirect 54,496) [7] which was higher than our findings. The total annual cost of diabetes in Sub Saharan Africa 1999-2011 was estimated USD 67.03 billion or USD 8,836 per diabetic patient [2].

Compression cost components (Table 8) revealed that the peak percentages of cost were incurred for drugs. Difference in the cost and proportions in these studies may be due to difference in the period of stu$\mathrm{dy}$, place, method of collecting the data, and economic values but in all studies the cost of diabetes increases manifolds with complications. Thus, affordability by patient may be the determinant of choice of therapy for poor patient and this high cost of therapy may lead to poor patient compliance and leading to complication which will compromise their quality of life [24]. Therefore, measure should be taken to promote rational drug selection, provision of regularly up-dated formulary and evidence-based standard treatment guidelines for promoting efficient use of limited resources [8].

Treatment with insulin costs 1.5 times higher as compared with oral hypoglycemic agents in the present study. Patients who were on insulin had to spend 2.8 times higher in South Indian tertiary care hospital study [19] 4 times higher in Ethiopia [16] while in Europe drug costs for managing type 2 diabetes were relatively low [25]. The annual per capita cost of type 2 diabetes patients was 3.1 times higher than average per capita health care expenditure in Iran (USD 842.6 vs. 269) and more than half of annual per capita diabetes cost was out-of-pocket expenditure [10].

Mean cost of illness by demographic characteristics was computed and both genders had comparable average cost and no statistically significantly association ( $p<0.05)$ with cost of illness. The finding was similar with the result obtained in Ethiopia [16]. Among different age groups, 65-74 age group was found the highest average cost (83.55 USD) followed by 55-64 age group with average cost of (73.38 USD). This revealed that the cost burden of the disease was significant in older population and ages were significantly associated ( $\mathrm{p}<$ 0.05 ) with cost of illness. The result was in line with Zimbabwe [17], Ethiopia [16] and United States of America study [30] findings.

The mean cost of illness was increased as the duration of the disease and the number of visits increases but it does not have a statistically significant effect on cost of illness ( $p>0.05$ ), but in urban Indians a positive correlation of increasing cost with duration of diabetes $(P=0.013)$ was observed [26]. The mean cost of complication and comorbidity was 75.28 USD and 77.44 USD was higher than those patients without complication and comorbidity and were significantly associated $(p<0.05)$ with cost of illness. Similarly, significant association was found on cost of illness with complication and comorbidity in Zimbabwe [17] and complication in Ethiopia [16]. Patients on dialysis had to spend 7.3 times higher, and patients with cardiac intervention had to spend 7.4 times higher than diabetic patients without any complication [19].

In the present study, diabetes complication costs 1.6 times higher than patients without complication. This was in line with South Indian tertiary care hospital study where annual cost of medication was 1.6 times higher for diabetes with complication compared to patients without complications [19]. The total annual cost for complications in Latin America and the Caribbean was USD 2,480 million [7]. Complications are also responsible for indirect costs in terms of productivity loss and absenteeism [13]. Hence further complication and comorbidity accelerates the cost of treatment and can impose an economic burden for the patient and the country as well which deters adherence to treatment. So, this burden of diabetes complications required for coordinated responses among different stake holders [22].

Analysis of cost components revealed that the high costs associated with the care of diabetic patients could be largely attributed to inpatient care and overall medication costs [27]. Diabetes currently accounts for approximately $10 \%$ of the total health resource expenditure and is projected to account for around $17 \%$ in 2035/2036 [9]. In WHO African region diabetes resulted a total economic loss of USD 25.51 billion in $2000[28,29]$. In view of the increasing global prevalence of diabetes, information from cost-of-illness studies should be used to increase awareness on economic bur- 
den of disease [7]. This awareness drives an urgent need for increased investments in the prevention and management of diabetes [10].

\section{Limitation of the Study}

The study reviewed patient medical records, there is some text illegibility, and this may introduce bias to the study. Due to the recall periods, results may be subject to recall bias. Moreover, social desirability bias might occur in collecting personal and accommodation costs.

\section{Conclusions}

Diabetes mellitus was an expensive illness and the direct medical costs constituted major segment in the treatment of illness and treatment with insulin costs 1.5 times higher as compared with oral hypoglycemic agents. Diabetes mellitus cost burden has been accelerated due to its complications by 1.6. In view of the increasing global prevalence of diabetes, information from cost-ofillness studies should be used to increase awareness and lobbying for allocation of resources. Awareness of economic burden drives the urgent need for increased investments in the prevention and management of diabetes.

\section{Acknowledgments}

We acknowledge the data collectors for their efforts to collect data and study participants for their involvement in the study.

\section{References}

1. World Health Organization (2013) Definition of diabetes mellitus and prevalence.

2. Hall V, Thomsen RW, Henriksen O, Lohse N (2011) Diabetes in Sub Saharan Africa 1999-2011: Epidemiology and public health implications. A systematic review. BMC public health 11: 564.

3. Feleke $Y$, Enquselassie $F$ (2005) An assessment of the health care system for diabetes in Addis Ababa, Ethiopia. Ethiopian Journal of Health Development 19: 203-210.

4. Watkins $P$, Alemu S (2003) Delivery of diabetes care in rural Ethiopia: An experience from Gondar. Ethiop Med J 41: 9-17.

5. Zhang $P$, Zhang $X$, Brown J, Vistisen $D$, Sicree $R$, et al. (2010) Global healthcare expenditure on diabetes for 2010 and 2030. Diabetes Res Clin Pract 87: 293-301.

6. International Diabetes Federation (2015) IDF diabetes atlas. ( $7^{\text {th }}$ edn), Brussels.

7. Barceló A, Aedo C, Rajpathak S, Robles S (2003) The cost of diabetes in Latin America and the Caribbean. Bull World Health Organ 81: 19-27.

8. Suleiman I, Fadeke O, Okubanjo O (2006) Pharmacoeconomic evaluation of anti-diabetic therapy in a Nigerian Tertiary Health Institution. Annals of African Medicine 5: 132-137.

9. Hex N, Bartlett C, Wright D, Taylor M, Varley D (2012) Estimating the current and future costs of Type 1 and Type 2 diabetes in the UK, including direct health costs and indirect societal and productivity costs. Diabet Med 29: 855-862.

10. Javanbakht M, Baradaran HR, Mashayekhi A, Haghdoost AA, Khamseh ME, et al. (2011) Cost-of-illness analysis of type 2 diabetes mellitus in Iran. PLoS One 6: e26864.

11. Abdelaziz MS, Rani SH, Ravindranath S, Shaik R, Kasim M, et al. (2015) Pharmacoeconomic evaluation of oral-hypoglycemic agents at hospital in Bangalore. IOSR Journal of Pharmacy and Biological Sciences 10: 46-50.

12. International Diabetes Federation (2013) IDF diabetes atlas. Brussels.

13. Kapur A (2007) Economic analysis of diabetes care. Indian J Med Res 125: 473-482.

14. Ambachew Y, Kahsay S, Tesfay R, Tesfahun L, Amare H, et al. (2015) Prevalence of diabetes mellitus among patients visiting medical outpatient department of Ayder referral Hospital, Mekelle, Ethiopia: Three years pooled. Int J Pharma Sci Res 6: 435-439.

15. Songer T, Glazner J, Coombs LP, Cuttler L, Daniel M, et al. (2006) Examining the economic costs related to lifestyle and pharmacological interventions in youth with type 2 diabetes. Expert Rev Pharmacoecon Outcomes Res 6: 315-324.

16. Assefa B, Wondimu A, Abrha S, Dinda SC, Demeke B, et al. (2014) Pharmacoeconomic evaluation of anti diabetic treatment at Ayder Referral Hospital, Mekelle, Ethiopia. Int J Pharm SciRev Res 25: 47-52.

17. Mutowo MP, Lorgelly PK, Laxy M, Renzaho A, Mangwiro JC, et al. (2016) The hospitalization costs of diabetes and hypertension complications in Zimbabwe: Estimations and correlations. J Diabetes Res 2016: 9754230.

18. Lester F (1983) Long-standing diabetes mellitus in Ethiopia: A survey of 105 patients. Diabetologia 25: 222-225.

19. Acharya LD, Rau N, Udupa N, Rajan MS, Vijayanarayana K (2016) Assessment of cost of illness for diabetic patients in South Indian tertiary care hospital. J Pharm Bioallied Sci 8: 314-320.

20. Emerging Risk Factors Collaboration, Sarwar N, Gao P, Seshasai SR, Gobin R, et al. (2010) Diabetes mellitus, fasting blood glucose concentration, and risk of vascular disease: A collaborative meta-analysis of 102 prospective studies. Lancet 375: 2215-2222.

21. Mohan V, Sandeep S, Deepa R, Shah B, Varghese C (2007) Epidemiology of type 2 diabetes: Indian scenario. Indian J Med Res 125: 217-230.

22. Idemyor V (2010) Diabetes in sub-Saharan Africa: Health care perspectives, challenges, and the economic burden of disease. J Natl Med Assoc 102: 650-653.

23. Mbanya JCN, Motala AA, Sobngwi E, Assah FK, Enoru ST (2010) Diabetes in sub-Saharan Africa. Lancet 375: 22542266.

24. Abdulganiyu G, Fola T (2014) What is the cost of illness of type II diabetes mellitus in a developing economy. Int $\mathrm{J}$ Pharm Pharm Sci 6: 927-931.

25. Jönsson B (2002) Revealing the cost of type II diabetes in Europe. Diabetologia 45: S5-S12.

26. Chandra $P$, Gogate B, Gogate $P$, Thite $N$, Mutha $A$, et al. (2014) Economic burden of diabetes in urban Indians. Open Ophthalmol J 8: 91-94.

27. Köster I, Von Ferber L, Ihle P, Schubert I, Hauner H (2006) The cost burden of diabetes mellitus: The evidence from Germany-the CoDiM Study. Diabetologia 49: 1498-1504.

28. Kirigia JM, Sambo HB, Sambo LG, Barry SP (2009) Economic burden of diabetes mellitus in the WHO African region. BMC Int Health Hum Rights 9: 6.

29. Agnes Erzse, Nicholas Stacey, Lumbwe Chola, Aviva Tugendhaft, Melvyn Freeman, et al. (2019) The direct medical cost of type 2 diabetes mellitus in South Africa: A cost of illness study. Glob Health Action 12: 1636611.

30. Association AD (2017) Comprehensive medical evaluation and assessment of comorbidities. Diabetes Care 2017, 40(Supplement 1): S25-S32. 